\title{
Design and Implementation of Automatic Gas Valve Control Mechanism for Biogas Plant
}

\author{
Nivedita Padole ${ }^{1} \mid$ Akshay Kadu ${ }^{2} \mid$ Dr. Sarika Patil ${ }^{3}$ \\ 1,2,3 Department of Electrical Engineering, Rajiv Gandhi College of Engineering and Research, Nagpur, Maharashtra, India
}

To Cite this Article

Nivedita Padole, Akshay Kadu and Dr. Sarika Patil, "Design and Implementation of Automatic Gas Valve Control Mechanism for Biogas Plant", International Journal for Modern Trends in Science and Technology, Vol. 06, Issue 05, May 2020, pp.: 72-77; https://doi.org/10.46501/IJMTST060512

\section{Article Info}

Received on 21-March-2020, Revised on 23-April-2020, Accepted on 29-April-2020, Published on 03-May-2020.

\section{ABSTRACT}

Biogas plants are slowly becoming popular as these are non-polluting, renewable energy source, reduces landfill and inexpensive. However, users from rural populations are still facing problems due to the absence of automation in biogas plants. Hence, the demand for automation and control is increasing so as to enhance the plant performance. This paper proposes a hardware implementation of automatic gas valve control mechanism for biogas plant. The automatic gas valve control system consists of LC5926H ON - OFF controller by which an automatic opening and closing of the gas valve has been carried out via solenoid valve. Based on the pressure inside the dome, the controller allows solenoid valve to perform the switching operation if the pressure inside the dome exceeds or fall below the preset value. This advanced mechanism provides more efficient and reliable solution to the existing biowaste systems by reducing human intervention and by avoiding the gas leakage.

KEYWORDS: Biogas Plant; on-off Controller; Solenoid Valve; Pressure; Dome; Gas Valve; Control Mechanism

Copyright (C) 2014-2020 International Journal for Modern Trends in Science and Technology

DOI: https://doi.org/10.46501/IJMTST060512

\section{INTRODUCTION}

The worldwide bio energy demand is strongly increasing in recent years. As per the Ministry of Power, the total all India installed capacity of power stations as on 29th February 2020 is recorded as $369427.97 \mathrm{MW}$ and of the renewable energy it is 86759.19 MW. The total installed capacity from biogas is $10001.11 \mathrm{MW}$ as per Ministry of Power. Ministry of New and Renewable Energy (MNRE) is implementing the National Biogas and Manure Management Programme (NBMMP) in all the states of the country. About 50.28 lakh household biogas plants are already installed in India as on 31 st March 2019; still around 144Million households do not have access to clean cooking fuel in India. To protect the household from the issues of indoor air pollution and high cost of refilling of LPG cylinders, Biogas can be a key source. Biogas is already being utilized for community transport, industrial heating, domestic cooking purpose and several applications [1]. Therefore, the worldwide bio energy demand is strongly increasing in recent years.

Biogas is formed from raw resources such as agricultural waste, manure, municipal waste, plant material, sewage, green waste or food waste [2]. Biogas includes a mixture of different gases generated by the breakdown of organic matter in the nonexistence of oxygen. Biogas consists of about 55-65 \% of methane, 35- $44 \%$ of carbon dioxide and bits of other gases, such as Hydrogen Sulphide, Nitrogen and Ammonia. This energy 
release lets biogas to be used as a fuel; it can be utilized for any heating purpose such as cooking. The installation of biogas plant and usage has been easier now days. The biogas plant is found to be the finest option for household having feed material, to become self-dependent for cooking gas and highly organic enriched bio manure.

As discussed earlier, according to MNRE and NBMMP, many of the users/farmers especially from the rural communities are still facing problems for the installation of the biogas plants, some of the issues are mentioned below:

Such as;

- Absence of automation in biogas system in villages.

- Difficulty in calculation of biogas consumption.

- Wastage of excess gas.

- Human intervention to operate gas valve.

- Pressure, temperature and PH are difficult to control.

- Monitoring and log maintaining is difficult due to absence of automation.

Presently, most of the inventions which have been carried out in this area [3]-[4] have provided automated systems for pressure control of biogas plants along with the gas relief system to control the excess pressure. These suggested systems include number of additional components, which are expensive and could not be affordable by the rural public. Also, many of the users from rural communities and industries are still facing problems due to labor-intensive, such as operating a gas valve by hand frequently depending upon its application for the control of plant parameters. Further, instead of gas relief system to control the excess pressure, the excess gas can be stored and utilized for many of the purposes such as electricity generation, cooking or transportation. Thus, the demand for automation and control is increasing so as to enhance the plant performance with better economy and reduced human intervention. Thus, the demand for automation and control is increasing so as to enhance the plant performance with reduced human intervention.

Many of the researchers working in this area have recognized several issues [5] related to biogas plant installations and their control. This paper presents a detailed case study [6]-[8] and the hardware implementation of automatic gas valve control mechanism for Biogas plant installed at Sanjeevan Oldage Home, Kanholibara, taluka Hingna, Nagpur, Maharashtra, India. The capacity of biogas plant installed at the abovementioned site is 25 cubic meter. The cow dung has been used as inlet manure. After surveying the selected site where biogas plant is installed the following problems are identified as:

- Absence of automation in controlling of gas valve.

- No device is installed for measurement of biogas production, and pressure of gas.

As per the investigation carried out at the selected site, it is observed that the leakage of gas during excess gas production and human involvement for plant operation is more. Hence, in this paper, this problem is resolved by converting the manual operation of gas valve to automatic control. The paper mainly focused on automation of gas valve control to reduce human involvement in the existing system.

\section{A Detailed Case Study}

The plant location has been identified in the village Kanholibara situated in taluka Hingna, named as Sanjeevan Oldage home, Nagpur, Maharashtra, India. They are using cow dung as manure for production of gas and the capacity of biogas plant is 25 cubic meter.

Table no 1: Salient Features of the Biogas Plant

\begin{tabular}{|l|l|}
\hline \multicolumn{1}{|c|}{ Particulars } & \multicolumn{1}{|c|}{ Salient Features } \\
\hline Digester & $\begin{array}{l}\text { Type: Floating dome } \\
\text { type } \\
\text { Diameter: } 12 * 12 \text { meter } \\
\text { Height: Total }=16 \text { feet, Above } \\
\text { ground }=6 \text { feet } \\
\text { Below ground = 10 feet } \\
\text { Supplier: Urja bio system pvt } \\
\text {.Ltd.,Pune, Maharashtra, India }\end{array}$ \\
\hline Scrubber & Height: 8 feet \\
\hline Storage balloon & $\begin{array}{l}\text { Capacity: } 10 \text { cubic } \\
\text { meter } \\
\text { Material: Neoprene / } \\
\text { PVC }\end{array}$ \\
\hline $\begin{array}{l}\text { Total area of plant } \\
\text { installation }\end{array}$ & $25 * 25$ meter sq \\
\hline Total capacity of plant & 25 cubic meter/day \\
\hline $\begin{array}{l}\text { Total cow dung } \\
\text { required for plant }\end{array}$ & $400-500$ kg/day \\
\hline $\begin{array}{l}\text { Organic manure } \\
\text { generated per day }\end{array}$ & $1000-1200$ liter/day \\
\hline Water required & $500-1000$ liter \\
\hline
\end{tabular}

\section{A. Existing System}

Fig. 1 shows the actual system installed at sanjeevan old age home, Kanholibara, taluka Hingna, Nagpur. In the given existing system floating dome type digester is used, because it has high reliability and fabricating skills than fixed dome type digester. The outlet of the dome is connected to main valve. Main valve is used for controlling the flow of gas. Two connections are taken out from the main valve. One is directly provided for cooking purpose and other is provided 
for storage of gas (balloon) via ball valve. Generally, ball valve is operated manually due to which human intervention has been increased. In this existing system, the user/farmer has to check many times whether the gas is exceeded or not especially during summer season. Thus, user has to go and turn on the gas valve manually such that the excess gas is stored in balloon; as soon as the excess gas is stored in the balloon, the user has to come back and turn off the gas valve. If the gas valve is not turned on, the gas escapes in the form of bubbles. Thus, one of the operators has to monitor the situation time to time.

As per the survey carried out at the selected site, it is observed that, in winter or rainy season gas production is low as compare to that of summer. From overall view, it has been found that human involvement is more in existing system. To reduce human involvement in existing system this paper mainly focused on making the gas valve control automated.

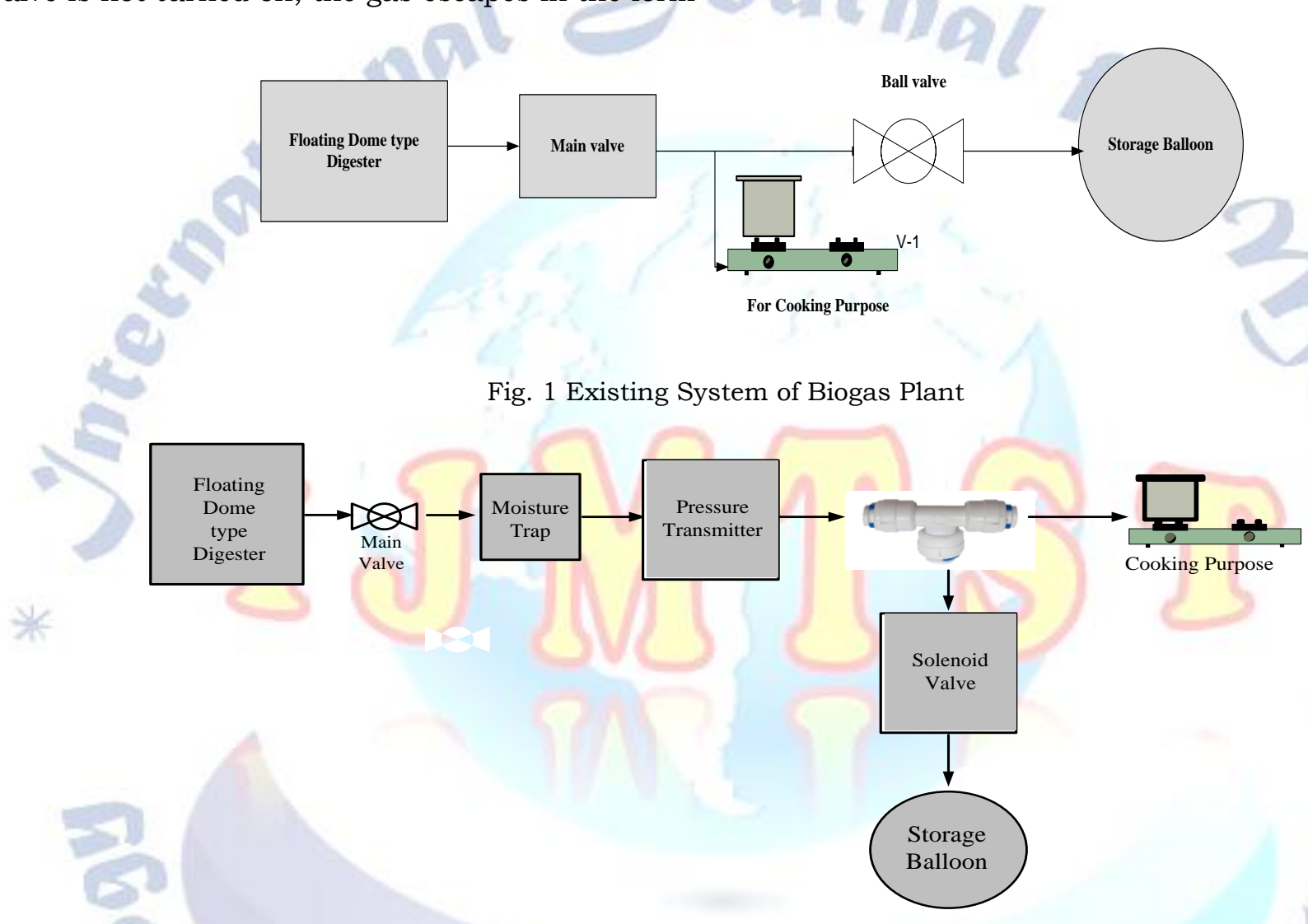

Fig.2 Proposed System of Biogas Plant

\section{B. Proposed System}

The aim of the modified system shown in Fig 2 is that when the excess gas is produced in the tank it should be stored automatically in the storage balloon without human involvement. From the main valve two connections are taken out, one connection is directly provided for cooking purpose and other connection is provided for storage of the excess gas in storage balloon. In between dome and storage balloon the Moisture trap, pressure transmitter, and solenoid valve are connected as depicted in Fig.2. Proposed system has been designed to overcome the issues recognized at the selected site such as; wastage of excess gas, increased human intervention, and the absence of automation to operate gas valve. The solution to the above said problems has been provided by the addition of three components i.e. ON-OFF controller, pressure transmitter and solenoid valve in the existing system.

The components used for the proposed system are: a. Pressure Transmitter

b. Solenoid valve

c. ON/OFF controller (LC5296-H)

a. Pressure Transmitter: Pressure transmitter is a device used for measurement of liquid and gases. Pressure transmitter converts mechanical pressure value into electrical signal. It is usually acts as a transducer.

b. Solenoid valve: Solenoid valve is an electromechanical actuated valve to control the flow of liquid and gases. It uses an electric 
current to generate magnetic field and thereby operate a mechanism which regulate opening of fluid/gas flow in valve.

c. ON/OFF controller (LC5296-H): The Controller (LC5296-H) accepts universal input and provides two relay output to perform various control and alarm function. This controller has two relay and gives two outputs. In this controller two set points can be set. If two set points are set at two different values, first relay will operate at first value and second relay will operate at second value.

\section{Working Principal Of The Proposed System}

Fig. 3 shows the circuit diagram of on/off controller LC5296H which controls the automatic operation of gas valve. The on/off controller operates on 230 Volt ac supply, which is then further converted to 24 Volt dc supply with the help of SMPS for the operation of pressure transmitter and solenoid valve. Positive terminal of the controller (LC5296-H) is connected to pressure transmitter and negative terminal is connected to solenoid valve. Change over relay is used to provide the set point for the pressure inside the dome. There is the presence of two relay, however, only one relay has been used as needed of only one set point. It consist of three relay input i.e N.C.(Normally Closed) , N.O.(Normally open) and common terminal. The relay set point can be decided on the basis of observations of the pressure taken on daily basis. Negative terminal of solenoid valve is connected to N.C. (Normally closed). As soon as the pressure inside the dome increases above the preset value, negative terminal of solenoid valve is connected to N.O. (Normally open) and the gas automatically stores in the balloon.

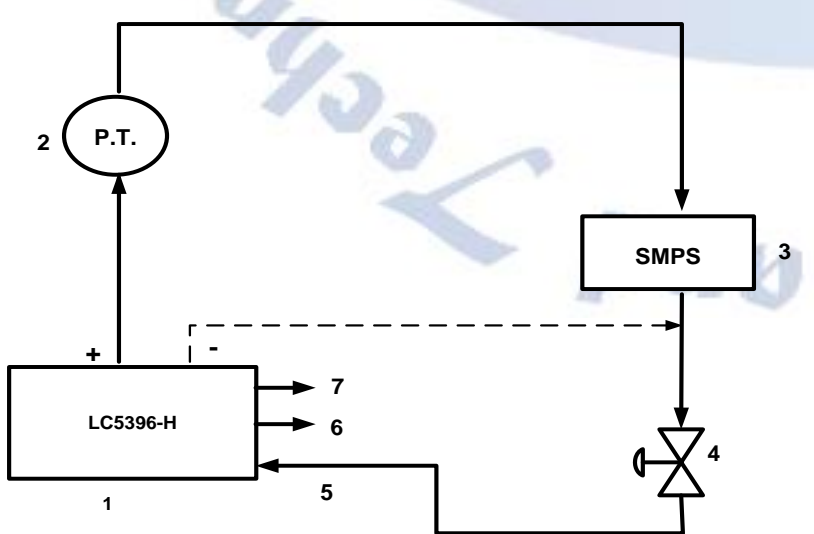

1. LC5296H controller 2. Pressure transmitter 3. S.M.P.S (Switch Mode Power Supply)

4. Solenoid valve 5. N.C. (Normally Closed) 6. N.O. (Normally
Open) 7. Common

Fig. 3 Circuit Diagram of the Control Mechanism

Pressure transmitter senses the gas pressure inside the dome and it is given to the on/off controller. In a controller, preset value is to be set for the gas pressure. Whenever the excess gas produced, the pressure in a floating dome increased and valve will turned ON automatically with the help of solenoid valve. In contrast, if pressure decreases below its preset value the valve will automatically turned OFF with the help of solenoid valve. This reduces the human effort and prevents escaping of the gas when excess gas is produced.

Table no 2: Hardware component specifications

\begin{tabular}{|c|c|c|}
\hline Sr. No & Components & Specifications \\
\hline 1. & $\begin{array}{c}\text { Pressure } \\
\text { transmitter }\end{array}$ & $\begin{array}{c}\text { Operating voltage }-24 \text { volts, } \\
\text { Operating current }-4-20 \mathrm{~mA}, \\
\text { Pressure range- 0 -160 mbar }\end{array}$ \\
\hline 2. & Solenoid valve & $\begin{array}{c}\text { Operating voltage }-24 \text { volts } \\
\text { Operating current - 2A }\end{array}$ \\
\hline 3. & $\begin{array}{c}\text { Controller } \\
\text { (LC5296-H) }\end{array}$ & $\begin{array}{c}\text { Operating voltage - 230volts } \\
\text { Operating current - 2 Amps }\end{array}$ \\
\hline
\end{tabular}

\section{PERFORMANCE ANALYSIS OF THE PLANT}

Pressure inside the dome with respect to time of the proposed system has been observed on two random days in the month of February 2019 and the readings of the pressure are noted for the half day accordingly. On the basis of the half day readings obtained, graphical analysis has been carried out which helps to decide the preset value of the pressure for relay.

Table no 3: Day 1 Readings

\begin{tabular}{|l|l|}
\hline Time & Pressure \\
\hline $7: 00 \mathrm{AM}$ & $8 \mathrm{mbar}$ \\
\hline $7: 30 \mathrm{AM}$ & $8 \mathrm{mbar}$ \\
\hline $8: 00 \mathrm{AM}$ & $8 \mathrm{mbar}$ \\
\hline $8: 30 \mathrm{AM}$ & $8.5 \mathrm{mbar}$ \\
\hline $9: 00 \mathrm{AM}$ & $9 \mathrm{mbar}$ \\
\hline $9: 30 \mathrm{AM}$ & $9 \mathrm{mbar}$ \\
\hline $10: 00 \mathrm{AM}$ & $9.2 \mathrm{mbar}$ \\
\hline $10: 30 \mathrm{AM}$ & $9.2 \mathrm{mbar}$ \\
\hline $11: 00 \mathrm{AM}$ & $10.1 \mathrm{mbar}$ \\
\hline $11: 30 \mathrm{AM}$ & $9.8 \mathrm{mbar}$ \\
\hline $12: 00 \mathrm{PM}$ & $7.6 \mathrm{mbar}$ \\
\hline $12: 30 \mathrm{PM}$ & $7 \mathrm{mbar}$ \\
\hline $1: 00 \mathrm{AM}$ & $7 \mathrm{mbar}$ \\
\hline
\end{tabular}




\section{Graphical Analysis of Gas Pressure vs Time}

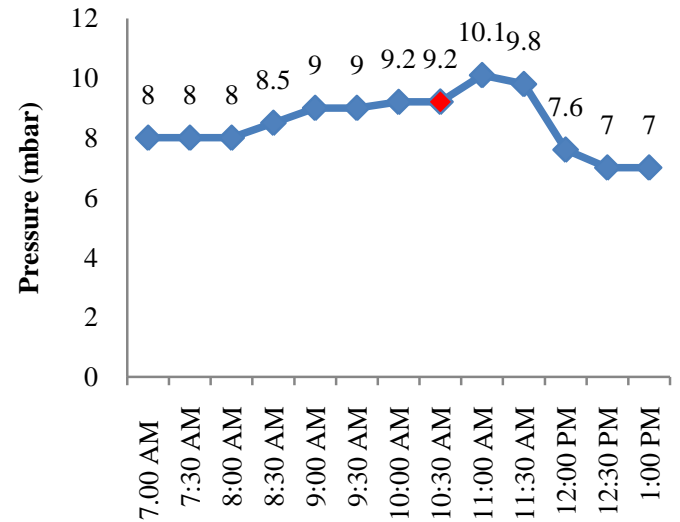

Fig. 4 Graphical analysis of Pressure vs Time; Day 1

Above Fig. 4 shows the graphical analysis of Pressure (mbar) with respect to time (hrs). As depicted in Fig. 6, it is observed that due to low temperature, pressure early in the morning from 7:00 AM to 8:00 AM, no gas is used and therefore pressure remains constant at $8 \mathrm{mbar}$. The use of gas has been started after 8:00 AM for domestic purpose. However, in spite of the gas usage for cooking, pressure goes on increasing and it reached up to $9.2 \mathrm{mbar}$ at 10:30 AM. As soon as the pressure approaches to $9.2 \mathrm{mbar}$, the gas starts escaping in the form of bubble. This excess gas is then stored in the balloon via solenoid valve by setting up the pressure preset value of the relay at 9.2 mbar. Decrease in the pressure can be seen after 11:00 AM. At around 12:00 PM, the gas has been used for making food, therefore pressure decreased to $7.6 \mathrm{mbar}$ and till 1:00PM pressure reduced to 7 mbar.

Table no 4: Day 2 Readings

\begin{tabular}{|c|c|}
\hline Time & Pressure (mbar) \\
\hline $7: 00 \mathrm{AM}$ & $7.8 \mathrm{mbar}$ \\
\hline $7: 30 \mathrm{AM}$ & $7.8 \mathrm{mbar}$ \\
\hline $8: 00 \mathrm{AM}$ & $8 \mathrm{mbar}$ \\
\hline $8: 30 \mathrm{AM}$ & $8.3 \mathrm{mbar}$ \\
\hline $9: 00 \mathrm{AM}$ & $8.6 \mathrm{mbar}$ \\
\hline $9: 30 \mathrm{AM}$ & $9 \mathrm{mbar}$ \\
\hline $10: 00 \mathrm{AM}$ & $9.5 \mathrm{mbar}$ \\
\hline $10: 30 \mathrm{AM}$ & $9.8 \mathrm{mbar}$ \\
\hline $11: 00 \mathrm{AM}$ & $9.7 \mathrm{mbar}$ \\
\hline $11: 30 \mathrm{AM}$ & $7.5 \mathrm{mbar}$ \\
\hline $12: 00 \mathrm{PM}$ & $7.5 \mathrm{mbar}$ \\
\hline $12: 30 \mathrm{PM}$ & $7.2 \mathrm{mbar}$ \\
\hline $1: 00 \mathrm{PM}$ & $7.2 \mathrm{mbar}$ \\
\hline
\end{tabular}

Graphical Analysis of Gas Pressure vs Time

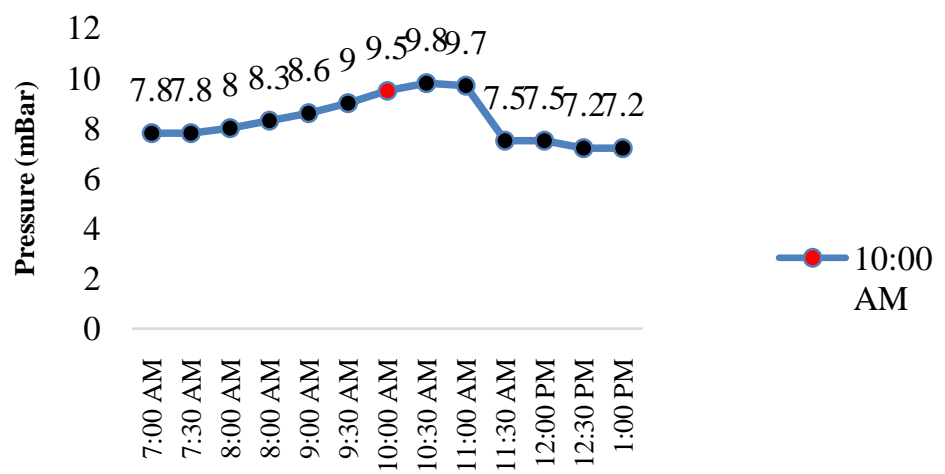

Time

Fig. 5. Graphical analysis of Pressure vs Time; Day 2

Similar kind of deviations in the pressure has been observed in the Fig. 5 of Day 2 also. Hence, by considering both the graphical representations, conclusion has been made that excess of gas is produced around $10 \mathrm{AM}$ to $11 \mathrm{AM}$ at 9.2 to 9.5 (mbar) pressure. This excess gas can be detected in the form of bubbles around the dome. Thus, relay has been set at 9.2 mbar preset value so as to store the excess gas in the balloon.

\section{CONCLUSION}

The paper mainly focused on Hardware implementation of automatic control mechanism for gas valve system of biogas plant installed at sanjeevan old age home, Kanholibara, taluka Hingna Nagpur. The existing system results into increased human intervention, difficult and time consuming system monitoring. Thus, the proposed system provides the LC5926H controller which is used to control the solenoid gas valve for the storage of excess gas in the storage balloon. This system provides automated gas valve control which reduces manual operation and prevents gas leakage during excess gas generation. This proposed mechanism is found to be beneficial for many of the users or farmers those having their biogas plants installed. The suggested system helps to enhance the biogas plant performance.

\section{REFERENCES}

[1] DurgaShankerMenaria, SurendraVerma, "Study of Combined Renewable Power System for Electricity Generation", Int. journal of research in advent technology, Vol.2, No.9, September 2014.

[2] ZianaZiauddin, "Production and Analysis of biogas using kitchen waste", Int. research journeral of engg. and technology, Vol. 2, July 2015.

[3] PromodShahu,SaritaSahu, Rajesh Purohit, VilasWarudkar, Arisutha S, Suresh S, "Automation in biogas plant for enhancement of efficiency \& safety", Int. 
conf. of matrerial processing and characterization, Vol4, no.4, p.p 5351-5356, 2017.

[4] T.K. Sethuramalingam and M. Karthighairasan, "Automatic Gas Valve Control System using Arduino Hardware", Bonfring International Journal of Power Systems and Integrated Circuits, Vol. 2, No. 3, Sept 2012.

[5] VadirajaAcharya, Vinay V Hegde, Anjan K., Manoj Kumar $\mathrm{M}$, "Iot (Internet Of Things) Based Efficiency Monitoring System for Bio-Gas Plants", IEEE Int. Conf.Computational Systems and Information Technology for Sustainable Solution (CSITSS), Dec 2017.
[6] Shailendra Kumar, B.P. Mishra and S.K. Patel, "Biogas plant in chattisgarh: A case study", Int. Jr. of Environmental science (cwejournal), vol. 11, No.2, pp. 599-603, April 2016.

[7] Mohamad Y Mustfa and RajnishCalay "Biogas from Organic Waste-A case study", Elsevier procedia engineering, Vol. 146, pp. 310-317, 2016.

[8] H. RavishankarKamath, P. N. Sreedhar, "Power generation using biogas- An Application to industries/rural area-case study", NPSC, IIT kharagpur, pp. 859-861, Dec 2002.

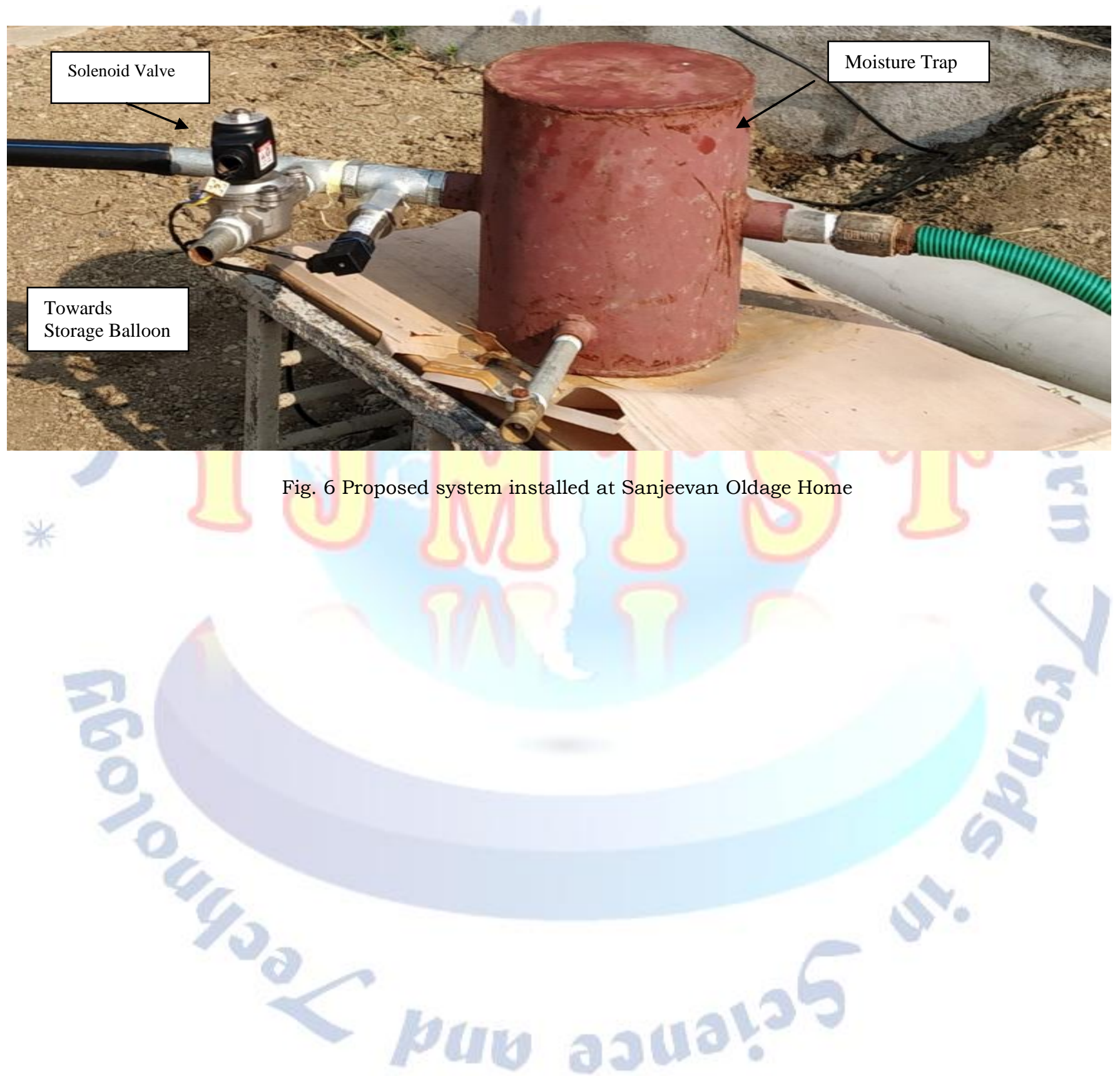

